\title{
32
}

\section{Früchte (Gitterrätsel)}

Trage die gesuchten Begriffe in das Gitter ein. Die Buchstaben in den grauen Feldern ergebenvon oben nach unten gelesen - das Lösungswort.

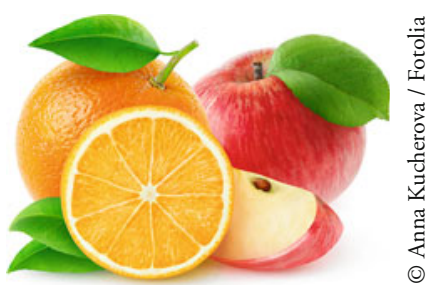

(1) Speicherorgan einiger Pflanzen, welches durch die Verdickung der Hauptwurzel entsteht

(2) eine beliebte behaarte Steinfrucht

(3) Fruchtstand weiblicher Hopfenpflanzen

(4) innerster, heller Teil der Kiwifrucht

(5) Frucht verschiedener Rosenarten, z. B. der Hundsrose

(6) deutsche Bezeichnung für Rucola

(7) In welcher Form wird $\mathrm{CO}_{2}$ in den Vakuolen von CAM-Pflanzen (z. B. bei der Ananas) gespeichert?

(8) Welcher Teil der Ingwerpflanze wird als Lebensmittel genutzt (biologische Bez.)?

(9) Welcher roten Sammelnussfrucht wird eine aphrodisierende Wirkung nachgesagt?

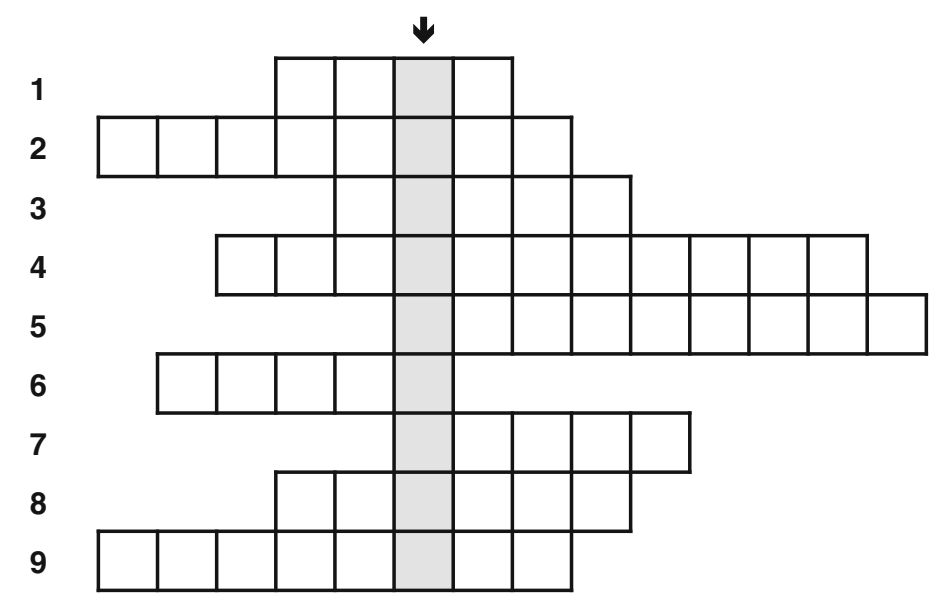

Lösung:

(C) Springer-Verlag Berlin Heidelberg 2016 C. Reinbold, Fetthenne, Moderlieschen, Warzenbeißer, DOI 10.1007/978-3-662-52817-4_32 